Revista Signos

2008, 41(67)

279-297

\title{
Una tipología del discurso de discriminación percibida en mapuches de Chile ${ }^{1}$
}

\author{
María Eugenia Merino \\ Daniel Quilaqueo \\ José Luis Saiz \\ Universidad Católica de Temuco \\ Chile
}

Resumen: Este trabajo presenta una tipología del discurso de la discriminación percibida por mapuches en Chile. Específicamente se describen los modos de discriminación percibida y se caracteriza el discurso de los participantes de la muestra, la que está constituida por 50 hombres y mujeres mapuches de la ciudad de Santiago y 50 de la ciudad de Temuco, Chile. La tipología incluye los ejes temáticos 'evento discriminatorio' y 'representación social'. El evento contiene once categorías de las cuales solo se considerarán las relativas al 'modo' y 'discurso' para el presente trabajo. Los resultados revelan la existencia de cuatro modos de discriminación percibida. El 'verbal' incluye sobrenombres, comentarios, chistes y burlas; el 'comportamiento' se expresa mediante observar, ignorar, evitar y segregar; la 'discriminación institucional' se realiza mediante sobreaplicación de leyes, normas y reglamentos; y la 'discriminación macro social' se concibe como desinterés de la sociedad mayoritaria hacia los mapuches y visión etnocéntrica de la historia oficial, entre otros. Por otra parte, el 'discurso de la discriminación percibida', analizado desde el modelo de análisis crítico del discurso de Merino (2006), revela que el discurso mapuche se estructura en base a un 'relato argumentativo', con actos de habla principalmente 'expresivos' y 'declarativos de uso', y estrategias semánticas locales de las cuales dos son transferidas desde la lengua mapuche.

Palabras Clave: Discurso, discriminación percibida, mapuches de Chile.

Recibido: 5-III-2007

Aceptado: $11-\mid-2008$
Correspondencia: María Eugenia Merino (mmerino@uct.cl). Tel: (56-45) 205314. Fax: 274456. Facultad de Educación, Universidad Católica de Temuco. Manuel Montt 56, Temuco, Chile. 


\title{
Discursive typology of perceived discrimination against mapuches in Chile
}

\begin{abstract}
This paper develops a discourse typology of perceived discrimination against mapuches in Chile. Specifically, this paper focuses on two out of eleven categories: "discriminatory event" and "social representations". The participants are 50 mapuche men and women from Temuco and 50 from Santiago. The findings reveal four types of perceived discrimination: "verbal", expressed by means of name calling, remarks, jokes and taunts; "behavioral", expressed by ignoring, looking and segregating; "institutional", through the application of norms; and "macrosicial", by a lack of interest from central society, cultural dominance and an ethnocentric interpretation of the nation history. On the other hand, the discourse of perceived discrimination, analysed using the method of critical discourse analysis proposed by Merino (2006), is structured on an "argumentative story", with dominance of expressive and declarative speech acts and local semantic strategies, two of which are transferred from the native language into oral Spanish..
\end{abstract}

Key Words: Discourse, perceived discrimination, chilean mapuches.

\section{INTRODUCCIÓN}

En los estudios sobre rechazo grupal en Chile existe amplia documentación sobre los fenómenos de estereotipos, prejuicio y discriminación, particularmente respecto del grupo indígena mapuche como son los trabajos de Cantoni (1978), Stuchlich (1985) y Montecino, Rebolledo, Willson y Campos (1993), desde la antropología, y los aportes de Saiz y Williams (1991, 1992), Dunbar, Saiz, Stela \& Sáez (2000), Saiz (2002, 2004), González, Manzi, Saiz, Brown, Zagefka, De Tezanos, Torres, Aldunate y Aravena (2003), y González, Saiz, Manzi, Brown, Sirlopú, Ordóñez y Millar (2003) desde la psicología social. Desde la perspectiva del análisis crítico del discurso se cuenta con los trabajos de San Martín (2001), Merino y Quilaqueo (2003, 2004), Merino y Pilleux (2004), Merino (2006), y Merino, Mellor, Quilaqueo y Saiz (2008), entre otros. Estos últimos autores se han abocado a conocer cómo la discriminación es percibida por los mapuches y los efectos psicosociales que ella genera.

De acuerdo con Plous (2003) el estudio de la discriminación percibida presenta al menos, tres beneficios. Primero, ofrece una compresión más completa del rechazo grupal al incluir la perspectiva del grupo discriminado. Segundo, estudiar la discriminación percibida proporciona información sobre las consecuencias que genera la exposición a la discriminación. Tercero, este tipo de estudio puede sugerir modos efectivos para que la sociedad en su conjunto y los perpetradores en particular tomen conciencia de los alcances del fenómeno y se puedan encontrar formas de reducir o eliminar las prácticas discriminatorias. Un beneficio adicional que provee estudiar la discriminación desde la visión de las víctimas es conocer en qué medida esta percepción concuerda con la discriminación que ejerce el otro grupo, indicando hasta qué medida pueden coincidir las percepciones de las víctimas con las prácticas discriminatorias que realizan los perpetradores. 
Los mapuches en Chile son conscientes del hecho de sufrir discriminación. Un estudio desarrollado por Cantoni (1978) sobre la percepción y experiencia de trato discriminatorio en mapuches reveló que el $82 \%$ de los adultos reportaba ser despreciado y tratado como inferior por los no indígenas por el hecho de ser mapuche. Según la percepción de dicho grupo, esta discriminación era más acentuada en la ciudad que en el campo, siendo más afectados aquellos mapuches que logran mayor acceso educacional, una posición económica regular y ascienden en una posición de clase. Tripailaf (1969), en un estudio realizado en la provincia de Valdivia revela la existencia de discriminación percibida en estudiantes mapuches de distintos niveles educacionales. Este autor demostró que a medida que se asciende en los niveles educacionales, la discriminación se va expresando de manera más encubierta. Los entrevistados manifiestan que el trato verbal vejatorio en el contexto educacional, y a veces también el maltrato físico en los niños más pequeños, origina paulatinamente en los mapuches un sentimiento de inferioridad y temor a participar en la sociedad chilena, opinión que es corroborada por sus padres. En 1999, una encuesta realizada en Mapuches por CERC-PARTICIPA revela que éstos perciben ser objeto de discriminación donde un $89 \%$ de la población mapuche a nivel nacional opina que son discriminados, principalmente en los ámbitos del trabajo, la justicia y la administración pública. Por su parte, López (2001) indagó el rechazo social percibido por mujeres mapuches pertenecientes a la organización Aukiñko Zomo de Temuco. Estas mujeres revelan ser objeto de distintas formas de discriminación por parte de empleadores y compañeras de trabajo no indígenas. Rojas y Sepúlveda (2002) muestran que los profesores mapuches de escuelas básicas de Temuco reconocen explícitamente sentirse discriminados por sus colegas y padres no mapuches. Merino y Quilaqueo (2004) en una muestra piloto de adultos mapuches de Temuco, encontraron que éstos perciben diversas expresiones de discriminación donde las "burlas", "menosprecio", "segregación" y "discriminación solapada" constituyen las categorías de mayor frecuencia. Desde una perspectiva psicológica, Casner, Navarrete, Rifo y Zañartu (2004) examinaron las representaciones sociales que jóvenes estudiantes mapuches de Temuco poseen sobre la experiencia de ser discriminados. Cinco son las categorías generales según las cuales los jóvenes representan la discriminación: como práctica social, como un fenómeno que emerge de las relaciones interétnicas, como un evento generador de impacto, como un fenómeno en constante transformación y como una forma de maltrato social. Merino, Quilaqueo y Saiz (2005) inician un estudio sobre la percepción de discriminación que poseen los mapuches en Chile la que es examinada a través del discurso espontáneo de los indígenas. Ante la ausencia en el campo lingüístico discursivo de una herramienta metodológica que sistematice la discriminación percibida en el discurso de los hablantes y tomando como base el modelo teórico de Mellor (2003) aplicado a indígenas e inmigrantes de Australia, Merino, Quilaqueo y Saiz (2005) diseñaron una tipología que organiza los principales ejes del discurso en torno a la discriminación percibida en una muestra de cien mapuches urbanos de las ciudades de Temuco y Santiago. Esta tipología se estructura en torno a dos ejes temáticos que son el 'evento discriminatorio' y la 'representación social' que los mapuches poseen acerca de cómo son percibidos por la 
población no indígena y está organizada en torno a categorías y subcategorías interrelacionadas temáticamente. El evento organiza las categorías narrativas relativas al evento discriminatorio bajo el cual se ordenan ocho subcategorías: etapa vital en que se vivenció la experiencia, el contexto y la situación, los hechos que constituyeron el evento discriminatorio, el perpetrador, el discurso de la víctima, su respuesta o reacción de ésta, y los efectos psicosociales generados por el evento. La representación social en tanto se revela a partir del análisis crítico del discurso de la muestra y describe las percepciones grupalmente compartidas por los mapuches sobre la forma como son percibidos por los no mapuches.

Para este trabajo en particular nos proponemos desarrollar una tipología del discurso de la discriminación percibida por mapuches en Chile a través de la caracterización de dicho discurso y su relación con los modos de discriminación percibida por los mapuches de Chile.

\section{Marco teórico}

Desde una perspectiva psicosocial, el prejuicio constituye el componente más afectivo del rechazo grupal en tanto los estereotipos constituyen el componente más cognitivo del rechazo grupal. El prejuicio es entendido como una actitud negativa o una predisposición a adoptar un comportamiento negativo hacia un grupo, que descansa sobre una generalización errónea y rígida (Allport, 1954). Los estereotipos y el prejuicio generalmente desembocan en problemas sociales cuando se traducen en comportamiento distintivamente hostil y vejatorio hacia exogrupos como es la discriminación (Allport, 1954; Harding, Proshansky, Kutner \& Chein, 1969). Uno de los problemas sociales generados por el prejuicio es la discriminación entendida como cualquier conducta desplegada por miembros de endogrupos que otorga un tratamiento injusto y desigual a los miembros de exogrupos en razón de su mera pertenencia al exogrupo (Allport, 1954). La discriminación está basada, entonces, en una distinción de categorías naturales o sociales que no guardan ninguna relación con los méritos, capacidades o acciones concretas de los miembros específicos de esas categorías.

Por otra parte, el fenómeno de discriminación percibida (DP en este trabajo) se refiere a la experiencia subjetiva de sentirse víctima de discriminación y constituye un proceso cognitivo inserto en un contexto sociocultural e histórico, que se actualiza mediante el discurso (Mellor, 2003). Este autor clasificó los eventos discriminatorios percibidos por aborígenes australianos e inmigrantes asiáticos en cuatro categorías: 'racismo verbal' que incluye sobrenombres y comentarios, 'comportamiento racista' que considera acciones como ignorar, 'evitar y observar' discriminación que incorpora prácticas de negación de oportunidades y maltrato por parte de la ley, y finalmente, 'racismo de macronivel' que incluye temas como despreocupación por los indígenas y dominancia cultural. La limitación de esta tipología es que da cuenta de categorías de DP 
desde una perspectiva estrictamente psicológica, considerando solo el evento discriminatorio, no considerando otras variables que son fundamentales en un estudio psicosocial y lingüístico del problema. En efecto, para describir en profundidad cómo un grupo percibe la discriminación hacia sus miembros es indispensable considerar antecedentes sociodemográficos de los entrevistados como género, edad y nivel educacional. Del mismo modo es relevante conocer la etapa vital en que el evento ocurrió, el contexto y situación específica, el origen étnico y nivel de autoridad del perpetrador y la respuesta o reacción de la víctima ante el hecho. A diferencia del modelo propuesto por Mellor (2003) que se focaliza solo en el tipo de evento, nuestra tipología considera los antecedentes sociodemográficos del entrevistado, el evento discriminatorio y la representación social que manejan los mapuches respecto de cómo son percibidos por los no mapuches. Este enfoque más amplio de variables que inciden en la DP otorga claridad acerca de la coherencia del discurso en tanto eje articulador de la DP y arroja importantes datos que permiten realizar un análisis crítico del fenómeno. Ello a su vez permite relevar los efectos psicosociales que la DP genera en el grupo bajo estudio.

Las prácticas discriminatorias de un determinado grupo se vinculan con la percepción de quienes son objeto de dichas prácticas mediante el procesamiento discursivo de los datos textuales que son sometidos al tratamiento de estrategias cognitivas. Los usuarios de una lengua desarrollan cuatro acciones estratégicas que vinculan los datos concretos con la teoría social que han acuñado. Estas son: la percepción selectiva y la interpretación de los rasgos discursivos y de comportamientos más sobresalientes del exogrupo, la interpretación de tales acciones, la construcción de modelos, y la conformación y uso de esquemas grupales. El resultado final de este procesamiento discursivo son los esquemas sociales o modelos abstractos generalizados, que constituyen las percepciones y creencias de los individuos (Kintsch \& van Dijk, 1983; van Dijk, 1996). Desde una perspectiva sociológica, dichos modelos se asemejan a la representación social que un grupo comparte en tanto miembros de una cultura e historia común. Respecto de este concepto Jodelet (1986: 472) plantea que:

"(...) las representaciones sociales se presentan bajo formas variadas, más o menos complejas (...) imágenes que condensan un conjunto de significados; sistemas de referencia que nos permiten interpretar lo que nos sucede, e incluso, dar sentido a lo inesperado (...)".

En este marco, la representación social constituye las categorías para clasificar las circunstancias, los fenómenos y a los individuos con quienes tenemos algo que ver.

Los procesos descritos más arriba otorgan al discurso un rol fundamental en la conformación de la percepción de discriminación que los miembros de un grupo manejan, dándose una estrecha relación entre discurso, discriminación, percepción y representación social. En nuestro trabajo 
entendemos el discurso como "un complejo conjunto de actos lingüísticos simultáneos y secuencialmente interrelacionados, que se manifiestan a lo largo y ancho de los ámbitos sociales de acción como muestras semióticas (...) y textos" (Wodak, 2003: 105). Desde esta perspectiva, nuestro análisis se sustenta primero sobre una base lingüística realizando análisis de los niveles semántico y pragmático para, desde allí, avanzar hacia un análisis crítico del discurso y una crítica sociodiagnóstica (Wodak, 2003). El análisis crítico del discurso (ACD) permite conocer cómo el hablante articula su discurso y cómo argumenta sus juicios y percepciones; asimismo permite acceder a los efectos psicosociales generados por la discriminación y a la representación social respecto del modo en que los miembros del grupo indígena son percibidos por los miembros de la sociedad mayoritaria. Este enfoque permite develar cómo las prácticas discursivas de las víctimas de discriminación revelan su percepción y la representación que ellos manejan de tales prácticas. El análisis crítico del discurso de la discriminación percibida constituye un quehacer disciplinario nuevo en nuestro país, especialmente aplicado al discurso de minorías indígenas como la cultura mapuche, que es el caso que estudiamos. La existencia de un discurso étnicamente prejuiciado y estereotipado en los no mapuches en su relación con la cultura mapuche, comprobado en las investigaciones de Merino y Pilleux (2003), Merino y Quilaqueo (2003), Merino (2004), Merino (2006), Merino, Quilaqueo, Pilleux y San Martín (2007), permite presuponer que los miembros del grupo indígena, en tanto víctimas de discriminación étnica, son conscientes de tales prácticas.

Para el ACD de la DP en el modelo propuesto por Merino (2006) permite develar cómo los mapuches interpretan los episodios discriminatorios y cómo perciben, reelaboran y se representan cognitivamente las atribuciones que los no mapuches realizan de su grupo. Este modelo de análisis considera los siguientes niveles: semántica global o temas, pragmático que incluye la argumentación y los actos de habla y de semántica local que analiza las estrategias y recursos estilísticos. Los 'temas' a nivel de semántica global se entienden como macroestructuras semánticas que guían el relato o descripción de un evento (van Dijk, 1984) que, para el caso del discurso de la DP, se derivan de los 'modos' de discriminación percibidos por los hablantes (por ejemplo uso de sobrenombres con referencia étnica, realización de comentarios intimidatorios y burlas). En el nivel pragmático se sitúa la 'argumentación' en tanto 'acto de habla complejo' (van Eemeren \& Grootendorst, 2002: 49) constituido por estrategias orientadas a justificar atribuciones y evaluaciones positivas o negativas que siguen determinadas secuencias argumentativas como narratio o resumen introductorio del tema, argumentatio o puesta en perspectiva que ubica el punto de vista del que habla y peroratio que recapitula y/o concluye el tema (Wodak, 2003). De la argumentación se derivan los topoi en tanto elementos vinculantes y concluyentes del argumento que, para efectos del discurso de la DP, se corresponden con los temas globales relevados del primer nivel de análisis. Las secuencias argumentativas son construidas sobre la base de 'actos de habla' asertivos, directivos, compromisorios, expresivos y declarativos según 
la tipología de Searle (1979). A estos actos Merino (2006) incorporó los 'declarativos de uso' de van Eemeren y Grootendorst (2002) por cuanto, para el análisis del discurso de la DP las explicaciones, aclaraciones, ampliaciones y definiciones de los diversos actos de habla facilitan e incrementan la comprensión del evento narrado. Finalmente, a nivel de semántica local las 'estrategias' son entendidas como una representación de una secuencia de acciones que se ejecutan para alcanzar una meta (van Dijk, 1984). Ellas muestran cómo se operativiza el acto de habla en función del argumento y los recursos utilizados para focalizar el 'topos' argumentativo y 'tema' de la DP.

\section{Metodología}

El enfoque utilizado para este trabajo es cualitativo. Este permite un intento de comprensión exploratoria y conceptualización del estudio de la discriminación percibida. Además, permite analizar los modos de discriminación que los mapuches perciben, lo que se realiza mediante el $A D C$ (supra). En este sentido se tienen en cuenta las dos características de este tipo de enfoque planteadas por Valles (1997) que es tener una visión general del fenómeno a estudiar, donde cada objeto de investigación puede ser entendido como un texto en un contexto, debiendo ser abordados ambos en su totalidad. En tanto, la segunda característica es la que impulsa a no perder contacto con la realidad inmediata, puesto que, la proximidad es un requisito indispensable. Para el desarrollo de la tipología que se presenta se parte del núcleo temático de la discriminación percibida por mapuches emigrados a los centros urbanos. Se trata de descubrir, captar y comprender una teoría de las relaciones interétnicas en contexto de dominación cultural, una explicación y un significado para reconstruir el proceso de formación de la representación de la discriminación percibida en los mapuches. Esta estrategia utilizada se basa en la teoría fundada en el sentido de generar "...una teoría derivada de los datos recopilados de manera sistemática y analizados por medio de un proceso de investigación" (Strauss \& Corbin, 2002: 13). La herramienta utilizada para el proceso preparatorio del análisis se fundamenta en la codificación abierta, axial y selectiva de estos últimos autores. La codificación abierta permite descubrir los conceptos claves a partir de los datos relevados del estudio, la axial en tanto relaciona las categorías narrativas con sus subcategorías permitiendo reagrupar los datos que se fragmentan durante la codificación abierta. Por último, en la codificación selectiva se integra y refina la teoría a los datos interrelacionados. Es decir en la integración los datos se vuelven teoría, se tienen en cuenta los conceptos que llegan a la posición de categoría como abstracciones que representan "no la historia de un individuo o grupo, sino la historia de muchas personas" (Strauss \& Corbin, 2002: 159). 


\subsection{Corpus}

La muestra está constituida por 50 hombres y mujeres mapuches residentes en Temuco y 50 residentes en Santiago, cuyas edades fluctúan entre 23 y 78 años (Media= 47.2, Desviación estándar=14,1). La mayoría de los participantes (87) son casados y cuarenta de ellos poseen cónyuge mapuche. El $84 \%$ de ellos habían completado al menos el primer año de Enseñanza Media, un $5 \%$ no tenía estudios o bien habían completado hasta el primer año básico, y un $11 \%$ había estudiado al menos un año de estudios universitarios. Casi la mitad de la muestra (42) eran o habían sido miembros de organizaciones mapuches y ocho de ellos habían desempeñado roles de liderazgo en ellas. Veinte participantes pertenecen a un estatus socioeconómico bajo, veinte a un estatus medio bajo, treinta a un estatus medio, dieciocho a un estatus medio alto y doce a un estatus alto.

\subsection{Recolección de la muestra}

Para el estudio se aplicó una entrevista semi-estructurada de preguntas abiertas. La primera parte de la entrevista consultó acerca de la percepción global del entrevistado sobre la discriminación hacia los mapuches en Chile, la segunda parte relevó las experiencias personales de discriminación vividas por el entrevistado solicitándoseles detallar etapa vital, perpetrador y contexto en que ocurrieron los eventos. Finalmente, la tercera parte, a través de preguntas como ¿qué cree usted que los no mapuches piensan de los mapuches? se buscó acceder a la representación social o forma como los mapuches se representan socialmente la percepción que los no mapuches poseen de ellos.

\subsection{Procedimiento}

Las entrevistas fueron aplicadas por tres entrevistadores mapuches entrenados por el equipo para tal efecto. Los participantes fueron contactados mediante organizaciones mapuches y a través de la técnica "bola de nieve" generada con los primeros entrevistados. La participación fue voluntaria y se aplicaron las entrevistas en los lugares de residencia de los entrevistados. Cada entrevista fue audiograbada y se realizó registro etnográfico de aspectos paralingüísticos, gestuales, proxémicos y de contexto relevantes para el problema en estudio.

\subsection{Tipología de la discriminación percibida}

La elaboración de la tipología implicó los siguientes pasos: lectura y análisis de las entrevistas para el levantamiento de las categorías que dieron origen a los dos grandes ejes y construcción de categorías y subcategorías por cada eje, lo que se realizó mediante un árbol taxonómico en versión electrónica, importación de las entrevistas categorizadas al software NVIVO 7, y final- 
mente, relación de categorías y subcategorías con segmentos representativos de discurso.

El 'evento' se desglosó en: etapa vital, modo, discurso, víctima, perpetrador y efectos psicosociales. La etapa vital clasifica el evento en términos de tres momentos de la vida del entrevistado: niñez, juventud y adultez. El modo incluye 'verbal', 'comportamiento', 'institucional' y 'macro social'. El verbal a su vez incorpora 'sobrenombres' con referencia étnica, a características físicas o color de piel, 'comentarios' que pueden ser generales o directos, chistes, burlas, amenazas y abuso que constituye un comentario verbal amenazante o inferiorizador acompañado de maltrato físico o psicológico. El modo 'comportamiento' da cuenta de acciones discriminatorias como ignorar, evitar, observar inquisitivamente, paternalizar, segregar, maltratar, negar identidad, mofas y gestos obscenos. En tanto el 'institucional' considera sobreaplicación de leyes, normas, reglamentos y negación de oportunidades socialmente adquiridas, todos comportamientos realizados por personas individualizables en organismos, oficinas, instituciones y servicios. Finalmente, en el modo 'macrosocial' el perpetrador se invisibiliza al interior de estructuras institucionales $\mathrm{y} / \mathrm{o}$ burocráticas, de modo que las acciones discriminatorias operan a nivel más global.

Por otra parte a la categoría 'discurso' se adscriben las subcategorías 'estructura argumentativa' con sus secuencias exordio, argumentatio y peroratio; además los 'actos de habla' asertivos, directivos, expresivos, compromisorios, declarativos y declarativos de uso; y las 'estrategias de semántica local' principalmente definición, ejemplificación, causa-efecto, comparación, reproducción de discurso directo, explicación, contraste, referencia a tiempo ancestral.

\section{Análisis y discusión}

\subsection{Temas de discriminación percibida}

El análisis del modo de la DP se realiza para acceder a los grandes temas que conforman la discriminación percibida por los mapuches. Los resultados muestran que la discriminación verbal mediante 'sobrenombres' constituyen el modo más recurrente, principalmente a través de referencia étnica como "indio", la que es percibida por los mapuches como muy ofensiva por su connotación de "primitivo", otorgado por los españoles a los indígenas, durante los primeros tiempos de la conquista del continente americano. Ser nombrado "indio" de manera recurrente por sus compañeros de trabajo es lo que le ocurre a T31:

(...) claro, porque aquí mismo en el mismo trabajo, aquí con mis colegas de trabajo (carraspea). En veces jugamos un partido de fútbol y yo me... juego al arco y ya porque en veces me pasan un gol ya me empiezan a retar "ya po' indio e mierda no atajas na"", dicen... O ya uno, si estamos compartiendo en una comida, cualquier cuestión, ya se toma uno... unos vasitos de más uno... dicen "puta el indio ya está tomando". 
Los comentarios directos e indirectos también son comunes en los intercambios verbales entre mapuches y no mapuches, especialmente comentarios implícitos que aluden a características estereotípicas atribuidas a los indígenas como "flojos", "ignorantes", "retrasados" que inferiorizan al indígena. Es el caso de T5 quien relata su experiencia durante el servicio militar:

Yo estaba en la sección de Telecomunicaciones, y entonces tenía que aprenderme el código Morse, ... y ellos (sargentos) entonces me decían "Este mapuchito, oye tu mapuchito, cuándo vai a aprender, ah?".

La referencia implícita realizada por el superior de T5 implica un "retraso cognitivo" atribuido a los mapuches en tanto grupo étnico, lo que se manifiesta discursivamente a través del uso de los diminutivos "ito/ita" que portan una carga semántica de "patronización" hacia el indígena (Merino \& Quilaqueo, 2003: 13).

Los chistes y burlas también presentan una recurrencia importante en el discurso de la DP de la muestra, particularmente aquellos que hacen remedo o mofa de formas de hablar el castellano y de los apellidos mapuches, como ocurrió con S2 y su hermana durante su educación básica:

(...) teníamos una profesora jefe que nos maltrataba, como... sicológicamente, por ejemplo, al llamarnos las... "las hermanitas Pichicon" decía "ya se sacaron nota roja", (...) nosotras notábamos que ella nos marcaba a nosotras dos... por ser... por tener un apellido mapuche y aparte todo eso... cuando pasaba la lista a nosotras nos daba pánico con mi hermana porque "ay se van a reír, se van a reír", y todo el tiempo era lo mismo...las compañeras decían "Pichicon, ah las hermanitas pichí, las hermanitas pichí", siempre se reían y a nosotras nos daba una vergüenza, nos hacían llorar, pero siempre fue así, toda la Básica.

Los contenidos proposicionales de sobrenombres en torno al concepto de "indio" y los comentarios directos e implícitos respecto del supuesto retraso cognitivo de los grupos indígenas mediante recursos léxico-semánticos como el diminutivo "ito/ita revelan la presencia de una ideología racista que subyace al discurso actual de los miembros de la sociedad mayoritaria. Esta ideología traída al continente por los conquistadores europeos se fundamenta en la clasificación de grupos humanos ubicados en un orden jerárquico considerando sus diferencias físicas y culturales de tal modo que éstas determinan el comportamiento individual por su mera pertenencia a dichos grupos (Todorov, 1991; Gresle, Panoff \& Perrin, 1994). Estas prácticas ideológico-discursivas en la sociedad chilena contemporánea fueron confirmadas por los estudios de Merino y Quilaqueo (2004) sobre el discurso de los chilenos respecto de los mapuches. Se reveló que las categorías de prejuicio más frecuentes en el discurso oral cotidiano de los no mapuches son 'racialismo' y 'paternalismo', esta última corresponde a una versión contemporánea del racismo clásico. La ideología racialista se expresa mediante atribuciones estereotipadas como "inferior", "primitivo", "retrasado", "ignorantes", "feo", "negro", "borracho" y "flojo"; en tanto el paternalismo se sustenta en la creencia de que 
el indígena es incapaz de cuidar de sí mismo y de progresar de modo que el no indígena debe asumir la resposabilidad de pensar y tomar decisiones por el indígena.

Por otro lado, la discriminación es percibida a través de comportamientos como inferiorizar, observar, ignorar, evitar el contacto o segregar a la persona indígena. T2 reportó la experiencia de segregación laboral de su hijo en una empresa alimenticia de Temuco.

(...) mi hijo mayor es promotor de la (señala una empresa alimenticia) y lo sacaron del (indica un supermercado para sectores acomodados) por sus características físicas... porque era muy bajo, le dijeron ahí... había que traer puros altos. Entonces... lo llevaron al (señala un supermercado para sectores populares), o sea, donde tiene que estar el indio... ese es el pensamiento de ellos (de sus jefes).

Entre los comportamientos discriminatorios más recurrentes se encuentra 'observar' que se realiza mediante variadas formas como mirar inquisitivamente, con gestos de burla o de desapruebo. Los entrevistados reportaron experiencias personales y de otros mapuches de haber sido observados por sus rasgos físicos, sus nombres mapuches, su vestimenta típica o modo particular de hablar el castellano. Asimismo, se reportan miradas de desconfianza debido a su condición mapuche, lo que ocurre principalmente en lugares concurridos como escuelas y liceos, transporte público, hospitales, bancos, multitiendas y oficinas públicas. Por ejemplo $\$ 8$, describe un evento ocurrido cuando acompañaba a su hija al hospital regional:

(...) lo he visto y lo... lo viví hace poquito no más con mi hija que recién viene saliendo del hospital...mi hija fue discriminada, o sea... no... no fue discriminada mi hija... ella nunca fue discriminada pero, pero... yo por el hecho de ser papá... como por el hecho de ser mapuche o por tener otro... otro color de piel u... otros rasgos de piel... este... te miran... te miran así como... como separado... te miran ahí (...).

Los comportamientos como ignorar, evitar el contacto y mirar u observar son interpretadas por los mapuches sobre la base de su calidad de indígena y asociadas al estereotipo "inferior"; se trata de una interpretación de racismo encubierto que destaca la diferencia física y cultural lo que constituye para el no indígena un objeto de sorpresa y observación.

A nivel institucional, la discriminación se realiza mediante acciones como negar oportunidades en los servicios públicos, discriminación en la escuela, en el trabajo, transporte y en el comercio. Los perpetradores actúan "amparados por la institución" de modo que si bien pueden ser individualizables, su responsabilidad se diluye en supuestas normas y reglas de la institución, tal como se aprecia en el testimonio de S32:

En la única oficina pública con este... ciudadano que después que... que me dice que estoy aprobado y todas las demás cosas, el año... 2001... que no tengo problema en nombrarlo si usted quiere, ...XX se llama y me rechazó, rechazó lo que la Ministra había 
aprobado, que yo lo presenté acá en Santiago y tenía que ir a Osorno... a presentarlo de nuevo...

Finalmente, la discriminación a nivel macrosocial es percibida en organismos gubernamentales, oficinas públicas, organismos judiciales y policiales en los que, a diferencia de los tipos verbales y de comportamiento, la discriminación es anónima y el perpetrador se invisibiliza al interior de estructuras jurídicas y constitucionales. Se identificaron tres tipos principales de discriminación macrosocial: dominancia cultural, que se expresa en la percepción de que los mapuches deben asimilarse a la cultura chilena al ser considerados un obstáculo para el progreso del país; dominancia educacional que fuerza al grupo indígena a participar en un sistema educacional nacional asimilador de su cultura; y perspectiva etnocéntrica de la historia nacional en cuanto a que la historia oficial del país ha sido distorsionada por historiadores que han reproducido estereotipos como "indios", "salvajes" y "violentos" lo que contribuye a socavar la imagen social y grupal de los mapuches ante la sociedad mayoritaria.

Los testimonios de mapuches emigrados a las ciudades de Santiago y Temuco apuntan a su situación de pobreza y niveles mínimos de educación formal como las consecuencias de la exclusión social y discriminación de mapuches que residen en el medio urbano, como lo plantea T1, profesional de las leyes.

(...) discriminación es la miseria y el analfabetismo, la pobreza extrema de un total de más o menos un millón setecientos mil de los nuestros en Santiago ¿acaso no es una forma de discriminación?, ¿acaso no es una forma de destierro?... Porque aquí no hay dónde caerse muerto, porque el noventa y cinco por ciento de las tierras fueron robadas... están plagadas de ciudades, de carreteras... de fundos... ¿qué hacer con la superpoblación?... se emigra y allá forman círculos de pobreza, la extrema pobreza de Santiago, en la periferia de Santiago, somos periféricos... en todas las capitales de provincia.

Este tipo de discriminación es percibida como acciones desarrolladas por la sociedad dominante que coartan la libertad y el derecho de la cultura del pueblo mapuche para desarrollarse y expresarse como tal, reduciéndolo a un grupo dominado y la mayor parte de las veces marginal. La discriminación macrosocial es la más compleja para la víctima de discriminación por cuanto resulta difícil identificar y eventualmente "educar" al perpetrador ya que, al ser anónima e invisible, subyace a la organización e institucionalidad política y social del país.

\subsection{El discurso de la discriminación percibida}

El análisis crítico del discurso de la DP se caracteriza por la presencia de una estructura argumentativa construida sobre la modalidad discursiva ngütram ${ }^{2}$ en la que concurren estrategias semánticas locales como narración, descripción, ejemplificación, reproducción de discurso di- 
recto y referencia a un tiempo ancestral. Se trata de una forma de un 'relato argumentativo' en que el punto de inicio es una introducción al evento discriminatorio o narratio, y donde los fundamentos y evidencia de soporte (argumentatio) se construyen en una estructura comparable al modelo de la narración. La argumentatio se desarrolla en torno a uno o varios sucesos, cada uno con la descripción de una acción discriminatoria, las reacciones del hablante y las consecuencias atribuidas al evento. Ocasionalmente, la argumentación culmina con una peroratio, epílogo o moraleja de la cual el hablante extrae una evaluación o lección, como se observa en la siguiente tabla.

Tabla 1. Relato argumentativo y secuencias argumentativas.

\begin{tabular}{|c|l|}
\hline Narratio & $\begin{array}{l}\text { "(...) yo creo que es difícil ser mapuche, estar dentro de esta sociedad (...) porque re- } \\
\text { sulta que, bueno hay muchas cosas, por ejemplo...es difícil ser mapuche, es difícil ser } \\
\text { extranjero en un lugar que uno... }\end{array}$ \\
\hline Argumentatio & $\begin{array}{l}\text {...es como si ésto, no fuera de uno, o sea no es como... o sea es difícil de que...compartir } \\
\text { algunos, algunas... costumbres se puede decir o que los huincas compartan una costum- } \\
\text { bre de uno, o sea eso es, es como más difícil. O por ejemplo en las mismas creencias, } \\
\text { que de repente ocurre cuando...ya en caso de enfermedad, supongamos, que uno esté } \\
\text { enferma, porque a mí me ocurrió y ahora en la actualidad...estando enferma, o sea, no } \\
\text { me encontraban absolutamente nada desde la perspectiva occidental, todos los exáme- } \\
\text { nes y miles de exámenes, incluso me dijeron que tenía el virus Hanta, entonces estuve } \\
\text { como siete o ocho horas en el hospital y después que me dijeron eso, me tuve que ir a } \\
\text { la casa y seguir haciéndome exámenes esperando el resultado de ellos. O sea, yo igual } \\
\text { creyendo que yo me podría a lo mejor mejorar desde la perspectiva mapuche... }\end{array}$ \\
\hline Peroratio & $\begin{array}{l}\text { entonces uno estando en una sociedad así occidental tiene que, no sé, ser de, como de } \\
\text { una línea, entonces, hay que hacer lo que a uno no le gusta hacer y tiene que hacerlo } \\
\text { igual..." [T03] }\end{array}$ \\
\hline
\end{tabular}

Los principales 'topoi' que se desprenden de los argumentos de la muestra dan cuenta de los principales modos y contextos donde ocurre la discriminación, por ejemplo "segregación y sobrenombres en la escuela", "comentarios y chistes en el trabajo", "sobreaplicación de normas en los servicios públicos", "trato inferiorizante en el transporte público y en el comercio".

El análisis reveló también la presencia de cuatro principales actos de habla: asertivos, expresivos, directivos y declarativos. Los asertivos componen el grueso del discurso de la muestra y describen comportamientos verbales y no verbales que conforman el evento discriminatorio, el modo en que el hablante evalúa tales acciones y cómo éstas afectaron su autoestima y, eventualmente también, su identidad étnica. Los expresivos en tanto revelan el grado emotivo que adquiere la experiencia discriminatoria al ser recordada donde se destacan emociones y sentimientos, y los efectos psicológicos y sociales atribuidos a la vivencia, como en "(...) y eso igual lo afecta a uno en alguna manera... como que a uno le cortan las alas" [S31]. 
Los directivos también constituyen una parte importante del discurso mapuche, a través de ellos los hablantes canalizan respuestas al evento discriminatorio como enfrentar, aclarar, enrostrar y modificar el comportamiento de los no mapuches, como en el siguiente ejemplo.

"(...) me dio mucha indignación que me hicieran esperar tanto rato y... bueno atiné... y le dije al gallo "bueno ¿hay algún problema, señor?, ¿qué problema hay? ¡explíqueme!". Y el tipo al final sale con una respuesta... absurda diciendo "no, que fuimos a revisar la cuenta, a verificar algunos detalles..." [T12].

Finalmente, a través de una importante presencia de declarativos de uso el hablante amplía información sobre el evento discriminatorio mediante ejemplificaciones y descripciones como en "(...) entonces mi mamá no usaba chamal, sí usaba rebozo, así de lana a telar, entonces cuando yo me enojaba, mi marido me decía: "oye ya te pusiste la pluma" [S43].

Por otra parte, las estrategias de semántica local más frecuentes son narración, descripción, ejemplificación, reproducción de discurso directo y referencia a tiempo ancestral, las que se ilustran a continuación.

narración:

"(...) porque me acuerdo que era un verano y anduvimos para allá para el lado de Icalma, entonces... estuvimos como quince días con mi familia, mi hermana, mi cuñado, mi hijo y mi sobrino. Y cuando llegué yo, o sea allá estuve súper bien y todo, y llegué como resfriada y con dolor de todo el cuerpo, síntomas de resfrío, pero no pensé que me iba a afectar tanto hasta que estuve una semana y ya no me podía levantar... no me podía el cuerpo, sentía que, no sentía mis piernas y no podía... a sea no comía tampoco me dolía el estómago también (...)" [T3]

descripción:

"(...) porque aquí no hay dónde caerse muerto, porque el noventa y cinco por ciento de las tierras fueron robadas... ahora están plagadas de ciudades, de carreteras... de fundos $(\ldots) "[\mathrm{~S} 30]$

ejemplificación:

"(...) porque la discriminación afecta...por ejemplo en el campo las chiquillas que estudian no quieren volver, y hay muchos que hasta se han cambiado hasta el apellido" [S35]

La estrategia semántica de reproducción de discurso directo provee al argumento con un efecto apelativo importante orientado a captar la solidaridad del oyente situándolo como interlocutor activo del evento, además sitúa al evento en tiempo presente. 
(...) le dije que ese baño para mí era monstruoso, que yo... yo era pobre, pero no era pa' tanto para yo ir a lavarme en ese baño...y me dijo "si ustedes los mapuches, los indios no se lavan"... pero "y porque no se lavan yo tengo que estar en lo mismo", le dije... "¿usted soportaría no lavarse?" [S35]

Finalmente, la estrategia semántica de referencia a un tiempo ancestral posee una marcada relevancia para la caracterización del discurso mapuche de la DP debido a que es una estrategia semántica originaria de la lengua mapuche. Se trata de una referencia a los consejos, valores, hábitos y costumbres de los ancianos de tiempos pretéritos, indefinidos desde la perspectiva occidental, cuyo rol es preservar la cultura y la lengua indígena a lo largo del tiempo y enseñar a los más jóvenes a saber relacionarse interculturalmente sin renunciar a su identidad étnica. Esta estrategia se grafica en el testimonio de $\mathbf{8} 8$ de la siguiente manera:

(...) se trata de saber vivir en las dos culturas, cómo poderlas compartir, los ancianos de antes decían no solamente hay que saber hablar en mapuche, contar en mapuche, responder en mapuche porque no... todo el tiempo voy a tener contacto solo con mapuche también... hay a tener contacto con la otra civilización... hablar en castellano, y eso fue lo que me pasó a mí [S8].

En resumen, el discurso mapuche de la DP posee una estructura de "relato argumentativo" que es, al parecer, transferido de la modalidad discursiva tradicional ngütram y se realiza principalmente mediante una secuencia argumentativa que prioriza el relato sobre una argumentación basada en datos y descripciones. La importante presencia de actos de habla asertivos, expresivos y declarativos de uso indican que la fuerza ilocucionaria del discurso de la DP se focaliza en la expresión de sentimientos y efectos de la discriminación y en proveer información de respaldo a juicios y evaluaciones de eventos discriminatorios. Ello es complementado por estrategias semánticas características del discurso mapuche como son referencia a un tiempo ancestral y reproducción de discurso directo que, al parecer, son transferidos por los participantes al discurso en español conservando su rol discursivo original. Ello constituye un supuesto que requerirá de mayor comprobación empírica.

\section{CONCLUSIÓN}

En este trabajo se ha desarrollado una tipología de la DP en el discurso de cien mapuches urbanos de las ciudades de Temuco y Santiago, específicamente nos hemos abocado a caracterizar el modo en que se percibe la discriminación y el discurso de la discriminación percibida. Los resultados revelan que los temas de DP más recurrentes son "discriminación en la educación", "discriminación laboral", y "discriminación en las oficinas y servicios públicos", los que coinciden con los 'topoi' más frecuentes derivados de las secuencias argumentativas. El modo más 
frecuente de DP es el verbal, particularmente a través de sobrenombres, comentarios, chistes y burlas. En tanto la modalidad comportamiento se expresa mayoritariamente mediante observar, ignorar, evitar y segregar.

El discurso de la DP, conformado por una estructura de relato argumentativo, actos de habla que destacan la expresión de emociones y sentimientos y estrategias semánticas orientadas a reproducir las prácticas discursivas de los perpetradores, refleja el estado actual de las relaciones interétnicas e interculturales entre mapuches y no mapuches en Chile. Asimismo, se constata la presencia de una ideología racista que subyace a las prácticas discursivas intergrupales del grupo dominante, características clave del racismo cotidiano descrito por Essed (1990, 1992). Este tipo de racismo del diario vivir a menudo se presenta encubierto, imperceptible y aparentemente intangible, pero el análisis crítico del discurso permite revelar cómo la dominación y la desigualdad, dentro de un contexto de relaciones sociales e interétnicas específicas, son llevadas a la práctica y reproducidas en el texto.

\section{REFERENCIAS BIBLIOGRÁFICAS}

Allport, G. (1954). The nature of prejudice. Massachusetts: Addison-Wesley.

Cantoni, W. (1978). Relaciones del mapuche con la sociedad nacional chilena. En UNESCO (Ed.), Raza y Clase en la Sociedad Postcolonial (pp. 227-334). Madrid: UNESCO.

Casner, M., Navarrete, R., Rifo, H. \& Zañartu, N. (2004). La discriminación étnica como contexto obstaculizador del desarrollo humano: Representaciones sociales de jóvenes mapuche en la ciudad de Temuco. Tesis de licenciatura, Universidad de La Frontera, Temuco, Chile.

CERC-PARTICIPA (1999) Encuesta: La discriminación a los mapuches. Santiago: Gobierno de Chile.

Dunbar, E., Saiz, J.L., Stela, K. \& Sáez, R. (2000). Personality and social group value determinants of outgroup bias: A cross-national comparison of Gough's Pr/To scale. Journal of Cross-Cultural Psychology, 31(2), 267-275.

Essed, P. (1990). Everyday racism: Reports from women of two cultures. Claremont, CA: Hunter House.

Essed, P. (1992). Alternative knowledge sources in explanations of racist events. M. McLaughlin, M. Cody \& S. Read (Eds.), Explaining one's self to others: Reason giving in a social context (pp. 199-224). Hillside, NJ: Lawrence Erlbaum.

González, R., Manzi, J., Saiz, J.L., Brown, R., Zagefka, H., De Tezanos, P., Torres, D., Aldunate, N. \& Aravena, T. (2003). Prejuicios y actitudes intergrupales: La experiencia de estudiantes de origen mapuche y chilenos no indígenas en Temuco, Chile. Presentado en el seminario internacional Prejuicio y Discriminación: Aspectos Psicológicos, Culturales y Legales, Pontificia Universidad Católica de Chile y British Council, Santiago, Chile. 
González, R., Saiz, J.L., Manzi, J., Brown, R., Sirlopú, D., Ordóñez, G. \& Millar, A. (2002). The contact hypothesis, social norms, and group salience: Predicting prejudice and positive affect towards minority groups in Chile. En R. González \& A. Voci (Coords.), Intergroup contact and prejudice reduction: Current development in theory and research. Simposio presentado en la $13^{\text {th }}$ General Meeting of the European Association of Experimental Social Psychology, San Sebastián, España.

Gresle, F., Panoff, M. \& Perrin, M. (Eds.) (1994). Dictionnaire des sciences humaines. Paris: Nathan.

Harding, J., Proshansky, H., Kutner, B. \& Chein, I. (1969). Prejudice and ethnic relations. En G. Lindzey \& E. Aronson (Eds.), The handbook of social psychology (pp. 1-76). Reading, MA: Addison-Wesley.

Jodelet, D. (1986). La representación social: Fenómenos, concepto y teoría. En S. Moscovici (Ed.), Psicología social II. Pensamiento y vida social. Psicología social y problemas sociales (pp. 469-494). Barcelona: Paidós.

Kintsch, W. \& van Dijk, T. (1983). Strategies of discourse comprehension. New York: Academic Press.

López, J. (2001). Percepciones de mujeres mapuches en torno al prejuicio étnico. El caso de la corporación de mujeres mapuches Aukinko Domo. Tesis de Licenciatura. Universidad Católica de Temuco, Temuco, Chile.

Mellor, D. (2003). Contemporary racism in Australia: The experiences of aborigines. Personality and Social Psychology Bulletin, 29(4), 474-486.

Merino, M. \& Quilaqueo, D. (2003). Estereotipos y prejuicio étnico hacia los mapuches en textos complementarios a la asignatura de Historia. Campo Abierto, 23, 119-135.

Merino, M. \& Pilleux, P. (2003). El uso de estrategias semánticas globales y locales en el discurso de los chilenos no mapuches de la ciudad de Temuco. Estudios Filológicos, 38, 111-119.

Merino, M. \& Quilaqueo, D. (2004). Ethnic prejudice against the mapuche in chilean society as a reflection of the racist ideology of the Spanish Conquistadors. American Indian Culture and Research Journal, 27(4), 105-116.

Merino, M. (2004). Prejuicio étnico en el habla cotidiana de los chilenos acerca de los mapuches en la ciudad de Temuco, Chile. En S. Coronel-Molina (Ed.), Culturas e ideologías en los Andes (pp. 193-210). Quito: Editorial Abya Yala.

Merino, M. \& Pilleux, P. (2004). El prejuicio étnico desde una perspectiva del análisis del discurso. ONOMAZEIN, 9, 168-186.

Merino, M., Quilaqueo, D., Pilleux, M. \& San Martín, B. (2007). Racismo discursivo en Chile. En T. van Dijk (Ed.), Racismo discursivo en América Latina (pp. 137-180). Barcelona: Editorial Gedisa.

Merino, M., Quilaqueo, D. \& Saiz, J.L. (2005). Informe de proyecto FONDECYT 1051047. Discriminación percibida presente en el discurso de mapuches y sus efectos psicosociales: Análisis del discurso de mapuches residentes en Temuco y Santiago.

Merino, M. (2006). Propuesta metodológica de análisis crítico del discurso de la discriminación percibida. Revista Signos. Estudios de Lingüística, 39(62), 453-469. 
Merino, M., Mellor, D., Quilaqueo, D. \& Saiz, J.L. (2008). Perceived discrimination amongst the indigenous mapuche people in Chile: Some comparisons with Australia. Journal Ethnic and Racial Studies (en prensa).

Montecino, S., Rebolledo, L., Willson, J. \& Campos A. (1993). Las múltiples dimensiones del empleo doméstico. Diagnóstico sobre inserción laboral de mujeres mapuches rurales y urbanas: Santiago, Chile. Santiago: Universidad de Chile, Facultad de Ciencias Sociales.

Plous, S. (2003). The psychology of prejudice, stereotyping, and discrimination: An overview. En S. Plous (Ed.), Understanding prejudice and discrimination (pp. 2-18). New York: McGraw-Hill.

Rojas, M. \& Sepúlveda, S. (2002). Prejuicio étnico respecto de profesores mapuches de la ciudad de Temuco. Tesis de licenciatura, Universidad Católica de Temuco, Temuco, Chile.

Saiz, J.L. \& Williams, J. (1991). Estereotipos adscritos al indígena mapuche por adultos no mapuches de Chile meridional. En Actas Coloquio Intercultural sobre Culturas Indígenas. Universidad Católica de Temuco y Universidad de la Frontera, Temuco, Chile.

Saiz, J.L. (2002). Atribución de estereotipos: Los indígenas mapuches que perciben los chilenos. En J. Morales, D. Páez, A. Kornblit \& D. Asún (Eds.), Psicología social (pp. 145-151). Buenos Aires: Prentice Hall-Pearson Educación.

Saiz, J.L. (2004). Nosotros y los mapuches: Discrepancias valóricas y prejuicio. Persona y Sociedad, 18(1), 129-144.

Saiz, J.L. \& Williams, J. (1992). El mapuche como objeto de percepción social: Categorización y estereotipos. En M. Gil \& F. Muldman (Eds.), La psicología latinoamericana: A 500 años del descubrimiento de América (pp. 255-256). Santiago: Universidad Nacional Andrés Bello.

San Martín, B. (2001). La representación de los mapuches en la prensa nacional. Tesis doctoral en Lingüística, Universidad Católica de Valparaíso, Valparaíso, Chile.

Searle, J. (1979). Speech Acts. New York: Cambridge University Press.

Strauss, A. \& Corbin, J. (2002). Bases de la investigación cualitativa. Técnicas y procedimientos para desarrollar la teoría fundamentada. Editorial Universidad de Antioquia, Medellín, Colombia.

Stuchlich, M. (1985). Las políticas indígenas en Chile y la imagen de los mapuches. Cultura, Hombre, Sociedad, 2(2), 159-194.

Todorov, T. (1991). Nosotros y los otros. Reflexión sobre la diversidad humana. México D.F.: Editorial Siglo XXI.

Tripailaf, D. (1969). Discriminación racial y social crea complejo de inferioridad en el pueblo mapuche. Revista Cauce, $\mathrm{VI}(46,47,48), 4-8$.

Valles, M. (1997). Técnicas cualitativas de investigación social: Reflexión metodológica y práctica profesional. Madrid, Síntesis.

van Dijk, T. (1984). Prejudice in discourse. An analysis of ethnic prejudice in cognition and conversation. Amsterdam/Philadelphia: Benjamins. 
van Dijk, T., Ting-Toomey, S., Smitherman, G. \& Troutman, D. (1996). Discourse, ethnicity, culture and racism. En T. van Dijk (Ed.), Discourse as social interaction (pp. 144-180). London: Sage Publications.

van Eemeren, F. \& Grootendorst, R. (2002). Argumentación, comunicación y falacias. Santiago: Ediciones Universidad Católica de Chile.

Wodak, R. (2003). El enfoque histórico del discurso. En R. Wodak \& M. Meyer (Eds.), Métodos de análisis crítico del discurso (pp. 101-141). Barcelona: Editorial Gedisa.

\section{NOTAS}

1 Este trabajo forma parte de los resultados del proyecto FONDECYT 1051047, Discriminación percibida presente en el discurso de mapuches y sus efectos psicosociales: Análisis del discurso de mapuches residentes en Temuco y Santiago; y del proyecto de Cooperación Internacional $N^{\circ} 7060032$, este último realizado en conjunto con el Dr. David Mellor de la Universidad de Deakin, Australia.

2 Ngütram es la modalidad discursiva más frecuente en el idioma mapuche. Se trata de una conversación dialógica donde el hablante narra hechos, expone ideas, describe circunstancias, ejemplifica y emite juicios de valor sin ser interrumpido por su interlocutor, quien tomará el turno una vez que el hablante haya concluido su relato o éste le haya cedido su turno. 